\title{
Editorial
}

\section{Development of Nursing Home Infection Control}

\author{
Philip W. Smith, MD
}

See also pages $306,312,341,358,362$

The demographics of aging America have been well documented. In 1994, one eighth of the total population was over 65 , and the most rapidly growing segment of the population is the age group 85 and older. ${ }^{1}$ The increasing number of elderly in the United States is the major factor leading to the rise in long-term-care residents, the vast majority of whom are over 65 years of age. According to some projections, approximately $40 \%$ of persons who turn 65 will spend some time during their life in a nursing home. ${ }^{2}$ Currently, approximately 1.5 million nursing home residents reside in approximately 17,000 nursing homes or long-term-care facilities (LTCFs) in this country. ${ }^{3}$ The number of nursing homes is nearly three times the number of acute-care hospitals in the United States.

Because LTCFs contain elderly residents with multiple underlying diseases in a closed environment, it is not surprising that nosocomial infections are a common occurrence. In 1985, it was estimated that 1.5 million infections occurred annually in US LTCFs ${ }^{4}$; that number is probably an underestimate of LTCF nosocomial infections currently. The incidence rate of 5 to 6 infections per 1,000 resident days is roughly comparable to the acute-care hospital nosocomial infection rate. ${ }^{5}$

Infection control in the LTCF has developed considerably over the last 20 years. LTCF infection control programs are virtually universal in this country. There are a number of studies documenting the incidence or prevalence of nosocomial infections in the LTCF and the descriptive epidemiology of these infections. Many LTCF infectious disease outbreaks have been described and so have some of the risk factors for nosocomial infection. The literature devoted to this topic is increasing rapidly, as seen by this issue of the Journal.

These advances in LTCF infection control occurred in spite of a number of inherent disadvantages in the field as compared to hospital infection control. LTCFs have considerably fewer resources and less expertise available for infection control efforts, and, in the vast majority of facilities, the nursing home infection control practitioner has multiple other duties in addition to infection control. ${ }^{6}$ Laboratory and radiology facilities are less readily available, and the medical record is much briefer than the typical acute-care hospital record, making nursing home research more difficult. Other research obstacles include limited reimbursement for medical care (compared to acute-care facilities), lesser funding due to the "low-tech" focus of long-term care, and the difficulty in obtaining informed consent for studies from a population with a high incidence of dementia. The goal of providing comfort care for the resident at life's end may conflict with infection control goals.?

LTCF infection control programs face unique challenges and are not well served by assuming that hospital infection control approaches will be uniformly successful in the LTCF. A Canadian consensus group developed surveillance definitions of infection that were specific for the LTCF, ${ }^{8}$ and LTCF infection control has been advanced by the publication of a number of consensus guidelines. The Society for Healthcare Epidemiology of America (SHEA) published guidelines on antimicrobial use, ${ }^{9}$ antimicrobial resistance, ${ }^{10}$ and vancomycin-resistant enterococci (VRE), ${ }^{11}$ all specific to the LTCF; a guideline on the approach to influenza in the LTCF is being developed. In addition, SHEA and the Association for Professionals in Infection Control and Epidemiology copublished the second edition of a guideline detailing the various components of an infection control program for the specific needs of an LTCF. ${ }^{12}$

From the Department of Internal Medicine, University of Nebraska Medical Center, Omaha, Nebraska.

Address reprint requests to Philip W. Smith, MD, Department of Internal Medicine, University of Nebraska Medical Center, 985400 Nebraska Medical Center, Omaha, NE 68198-5400.

99-ED-022. Smith PW. Development of nursing home infection control. Infect Control Hosp Epidemiol 1999;20:303-305. 
While all of the above accomplishments are commendable, there is still a great need for additional research. Studies on nosocomial infections in the LTCF need to be updated and expanded to new pathogens. An example is the study of a nursing home outbreak presented in this issue of the Journal. ${ }^{13}$ As would be expected, outbreaks of diarrhea in this frail, elderly, and often incontinent population frequently involve large numbers of residents and staff. Marx et al provide a very thorough investigation of a Norwalk-like virus outbreak of gastroenteritis that affected $57 \%$ of the residents and $35 \%$ of the employees in an LTCF. Four residents were hospitalized and three died. A point source could not be identified; person-toperson spread was suggested by the epidemiology of the outbreak. Stool specimens were analyzed by electron microscopy and polymerase chain reaction. This study provides additional information on an important cause of morbidity using techniques not normally available to the nursing home. It underscores the importance of application of new microbiological techniques to undiagnosed epidemics and the importance of involving the health department in these outbreak investigations.

The increasing national incidence of VRE in acutecare hospitals has now become an infection control issue in LTCFs as well. ${ }^{14}$ In this issue of the Journal, there are two Canadian reports dealing with VRE in the LTCF. Greenaway and Miller describe the absence of secondary cases after three patients colonized with VRE were admitted to LTCFs; cultures of contacts and environment were obtained. ${ }^{15}$ Armstrong-Evans et al discuss control of transmission of VRE in an LTCF by isolation (gloves and gowns were used for resident contact, and colonized residents were cohorted). No secondary cases occurred after the above measures were instituted, and the three residents who survived longer than 2 months became culturenegative for VRE. ${ }^{16}$

There is a large body of literature on the epidemiology of VRE in the acute-care hospital but very few reports discussing this problem in the LTCF. The two Canadian studies are welcome additions to the literature. The Greenaway and Miller study ${ }^{15}$ is encouraging, although it should be viewed with some caution in light of the small number of patients involved. All of their colonized patients were admitted to private rooms with emphasis on hand washing and room disinfection. Many LTCFs do not have sufficient private rooms or handwashing facilities for isolation even if VRE-colonized patients are recognized. The authors noted a high level of compliance with recommended infection control measures, probably a reflection of the substantial educational program they undertook. Such an intense educational program would be logistically challenging for many LTCFs.

Similarly, the control of VRE spread in an LTCF by the Toronto group ${ }^{16}$ was encouraging but may not be universally applicable. Cohorting of residents and the wearing of gowns and gloves for resident contact by staff are ideal but difficult to implement in some LTCFs. The hospital literature suggests that VRE carriage more typically occurs for long periods of time rather than the short duration seen in this study, thus imposing additional costs for epidemic containment. ${ }^{17}$ As the authors point out, extensive laboratory backup is necessary to support a VRE control effort. The article very appropriately analyzed costs incurred during control of this outbreak. The total cost of investigation and control was slightly over $\$ 12,000$, an amount that would pose a considerable burden for many LTCFs. A great deal of education was involved in this VRE control effort, and the expense of informal educational efforts often is not included in cost estimates. I suspect that many facilities will not be fortunate enough to contain a VRE outbreak so quickly.

Another article in this issue of the Journal reflects the more advanced state of the art regarding control of VRE in the hospital setting. Lautenbach et $\mathrm{a}^{18}$ describe the independent risk factors for VRE acquisition in patients with VRE bacteremia and calculate the attributable mortality for VRE bacteremia. VRE was not significantly associated with increased mortality after accounting for severity of illness and age. Comparable data are not available for the LTCF setting and certainly would be more difficult to obtain, since this study relied on a detailed medical-record analysis.

This issue's theme of LTCF infection control is further enhanced by the discussion of antibiotic-resistance issues in the "Topics in Long-Term Care" column. ${ }^{19} \mathrm{Dr}$. Bradley reviews the literature on resistant organisms, such as VRE and methicillin-resistant Staphylococcus aureus, in the LTCF and provides a rational approach to isolation in that setting.

The excellent articles in this month's Journal demonstrate the expanding knowledge in the field of longterm-care infection control, as well as the application of more sophisticated epidemiological and microbiological techniques to infection control in that setting. As medical care has moved from the acute-care hospital to other arenas (home health care, outpatient care, and long-term care), infection control programs have followed.

There are a few studies that elucidate epidemiological mechanisms of nosocomial infections in the LTCF, but many more are needed. Examples include studies on hand contamination, ${ }^{20}$ nosocomial transmission of gastroenteritis to laundry workers, ${ }^{21}$ the definition of the importance of ill employees in nursing home outbreaks of viral gastroenteritis, ${ }^{22}$ and the potential role of infected body fluids ${ }^{13}$ or the environment. ${ }^{15}$

There is a great need for studies on the effectiveness of specific infection control interventions, such as education, ${ }^{23}$ handwashing, ${ }^{24}$ or isolation. ${ }^{16}$ Early attempts have been made to examine the overall efficacy of infection control programs in the LTCF 25 ; it would be ideal to have costefficiency data on infection control programs as well.

All the efforts to enhance infection control in the longterm-care setting have to keep in mind the dignity of the resident who is approaching the end of life and the fact that this facility is a home for the resident. Infection control measures will, one hopes, not create undue work for busy LTCF per- 
sonnel or make the resident's stay unpleasant. To paraphrase John Steinbeck, “A sad soul can kill you as surely as a germ."

\section{REFERENCES}

1. Hobbs FB, Damon BL. 65 Plus in the United States. US Bureau of the Census. Current Population Reports, Special Studies. April 1996:23-190.

2. Kemper P, Murtaugh CM. Lifetime use of nursing home care. $N$ Engl J Med 1991;324:595-600.

3. Healthcare Financing Administration. Online survey, certification and reporting data, March 1997.

4. Haley RW, Culver DH, White JW, et al. The nationwide nosocomial infection rate: a new need for vital statistics. Am J Epidemiol 1985;121:159-167.

5. Smith PW. Nursing home infection control: a status report. Infect Control Hosp Epidemiol 1998;19:366-369.

6. Nicolle LE, Garibaldi RA. Infection control in long-term-care facilities. Infect Control Hosp Epidemiol 1995;16:348-353.

7. Mott PD, Barker WH. Treatment decisions for infections occurring in nursing home residents. J Am Geriatr Soc 1988;36:820-824.

8. McGeer A, Campbell B, Emori TG, Hierholzer WJ, Jackson MM, Nicolle LE, et al. Definitions of infection for surveillance in long-term care facilities. Am J Infect Control 1991;19:1-7.

9. Nicolle LE, Bentley D, Garibaldi R, Neuhaus E, Smith P, the SHEA LongTerm-Care Committee. Antimicrobial use in long-term-care facilities. Infect Control Hosp Epidemiol 1996;17:119-128.

10. Strausbaugh LJ, Crossley KB, Nurse BA, Thrupp LD, the SHEA LongTerm-Care Committee. Antimicrobial resistance in long-term-care facilities. Infect Control Hosp Epidemiol 1996;17:129-140.

11. Crossley $\mathrm{K}$, the SHEA Long-Term-Care Committee. Vancomycin-resistant enterococci in long-term-care facilities. Infect Control Hosp Epidemiol 1998;19:521-525.

12. Smith PW, Rusnak PG. Infection prevention and control in the longterm-care facility. Infect Control Hosp Epidemiol 1997;18:831-849.

13. Marx A, Shay DK, Noel JS, Brage C, Bresee JS, Lipsky S, et al. An outbreak of acute gastroenteritis in a geriatric long-term-care facility: combined application of epidemiological and molecular diagnostic methods.
Infect Control Hosp Epidemiol 1999;20:306-311.

14. Bonilla HF, Zervos MA, Lyons MJ, Bradley SF, Hedderwick SA, Ramsey MA, et al. Colonization with vancomycin-resistant Enterococcus faecium: comparison of a long-term-care unit with an acute-care hospital. Infect Control Hosp Epidemiol 1997;18:333-339.

15. Greenaway CA, Miller MA Lack of transmission of vancomycin-resistant enterococci in long-term-care facilities. Infect Control Hosp Epidemiol 1999;20:341-343.

16. Armstrong-Evans M, Litt M, McArthur MA, Willey B, Cann D, Liska S, et al. Control of transmission of vancomycin-resistant Enterococcus faecium in a long-term-care facility. Infect Control Hosp Epidemiol 1999;20:312-317.

17. Boyce JM. Vancomycin-resistant enterococci: pervasive and persistent pathogens. Infect Control Hosp Epidemiol 1995;16:676-679.

18. Lautenbach E, Bilker WB, Brennan PJ. Enterococcal bacteremia: risk factors for vancomycin resistance and predictors of mortality. Infect Control Hosp Epidemiol 1999;20:318-323.

19. Bradley SF. Issues in the management of resistant bacteria in longterm-care facilities. Infect Control Hosp Epidemiol 1999;20:362-366.

20. Larson E, Bobo L, Bennett R, Murphy S, Seng ST, Choo JTE, et al. Lack of care giver hand contamination with endemic bacterial pathogens in a nursing home. Am J Infect Control 1992;19:11-15.

21. Standaert SM, Hutcheson RH, Schaffner W. Nosocomial transmission of Salmonella gastroenteritis to laundry workers in a nursing home. Infect Control Hosp Epidemiol 1994;15:22-26.

22. Rodriguez EM, Parrott C, Rolka H, Monroe SS, Dwyer DM. An outbreak of viral gastroenteritis in a nursing home: importance of excluding ill employees. Infect Control Hosp Epidemiol 1996;17:587-592.

23. Daly PB, Smith PW, Rusnak PG, Jones MB, Giuliano D. Impact on knowledge and practice of a multiregional long-term care facility infection control training program. Am J Infect Control 1992;20:225233.

24. Ehrenkranz NJ, Alfonso BC. Failure of bland soap handwash to prevent hand transfer of patient bacteria to urethral catheters. Infect Control Hosp Epidemiol 1991;12:654-662.

25. Goldrick BA. Infection control programs in skilled nursing long-term care facilities: an assessment, 1995. Am J Infect Control 1999;27:4-9. 